\title{
Time dependent alterations of serum matrix metalloproteinase-1 and metalloproteinase-1 tissue inhibitor after successful reperfusion of acute myocardial infarction
}

\author{
Satoshi Hirohata, Shozo Kusachi, Masahiro Murakami, Takashi Murakami, Issei Sano, \\ Tomoko Watanabe, Issei Komatsubara, Jun Kondo, Takao Tsuji
}

\begin{abstract}
Objective-To test the hypothesis that changes in serum matrix metalloproteinase-1 (MMP-1) and tissue inhibitors of metalloproteinase-1 (TIMP-1) after acute myocardial infarction reflect extracellular matrix remodelling and the infarct healing process.

Patients-13 consecutive patients with their first acute myocardial infarction who underwent successful reperfusion.

Methods-Blood was sampled on the day of admission, and on days $2,3,4,5,7,14$, and 28. Serum MMP-1 and TIMP-1 were measured by one step sandwich enzyme immunoassay. Left ventricular volume indices were determined by left ventriculography performed four weeks after the infarct.
\end{abstract}

Results-Serum concentrations of both MMP-1 and TIMP-1 changed over time. The average serum MMP-1 was more than 1 SD below the mean control values during the initial four days, increased thereafter, reaching a peak concentration around day 14 , and then returned to the middle control range. Negative correlations with left ventricular end systolic volume index and positive correlations with left ventricular ejection fraction were obtained for serum MMP-1 on day 5, when it began to rise, and for the magnitude of rise in MMP-1 on day 5 compared to admission. Serum TIMP-1 at admission was more than 1 SD below the mean control value, and increased gradually thereafter, reaching a peak on around day 14. Negative correlations with left ventricular end systolic volume index and positive correlations with left ventricular ejection fraction were obtained for serum TIMP-1 on days 5 and 7, and for the magnitude of rise in TIMP-1 on days 5 and 7 compared to admission.

Conclusions-Both MMP-1 and TIMP-1 showed significant time dependent alteration after acute myocardial infarction. Thus MMP-1 and TIMP-1 may provide useful information in evaluating the healing process as it affects left ventricular remodelling after acute myocardial infarction.

(Heart 1997;78:278-284)

Keywords: left ventriculography; ventricular remodelling; matrix metalloproteinase-1; tissue inhibitor of metalloproteinase-1; fibrosis
Left ventricular volume is one of the major prognostic factors after acute myocardial infarction. ${ }^{12}$ Ventricular remodelling is thus important with respect to prognosis. ${ }^{34}$ The extracellular matrix plays a vital role not only in the maintenance of ventricular shape but also in ventricular function. Collagen is apparently an essential component of the extracellular matrix, and collagenases and their inhibitors play crucial roles in extracellular matrix homeostasis. ${ }^{5}$ Recent biological studies have identified several distinct matrix metalloproteinases (MMP) and tissue inhibitors of metalloproteinases (TIMP) and have delineated their characteristics. ${ }^{56}$ The important roles of MMP and TIMP in cardiovascular disease have been reviewed by Dollery et al. ${ }^{7} \mathrm{MMP}-1$, a $54 \mathrm{kDa}$ interstitial collagenase, degrades several types of collagen and other extracellular matrix components, including types I and III collagen, the major types of collagen in the collagen matrix. ${ }^{5}$ TIMP-1, a $29.5 \mathrm{kDa}$ sialoglycoprotein, forms a complex with MMP- $1^{89}$ and acts as a native inhibitor of MMP-1. Inhibitory regulation of MMP-1 activity is mediated in part by TIMP-1. MMP-1 and TIMP-1 thus contribute bidirectionally to the control of collagen matrix maintenance. During extracellular matrix remodelling, degradation and reformation of extracellular matrix occur, and both MMP and TIMP contribute to this process through the balance of their activities. We hypothesised that changes in serum MMP and TIMP concentrations reflect the extracellular matrix remodelling involved in the infarct healing process and that these changes would thus be correlated with left ventricular volume indices. Although there are reports of increased expression of TIMP in chronic liver disease ${ }^{10}$ and rheumatoid arthritis, ${ }^{11}$ there are none on changes in serum MMP and TIMP after acute myocardial infarction. We therefore examined the relations of serum MMP-1 and TIMP-1 to left ventricular volume indices obtained by left ventriculography in patients after myocardial infarction.

\section{Methods}

PATIENTS

To determine the sequential changes in serum MMP-1 and TIMP-1 from the infarct onset day, we studied 13 consecutive patients with their first acute myocardial infarct who were admitted within 12 hours of infarct onset and underwent reperfusion by coronary angio-

The First Department
of Internal Medicine,
Okayama University
Medical School,
Okayama 700, Japan
S Hirohata
S Kusachi
M Murakami
T Murakami
I Sano
T Watanabe
I Komatsubara
J Kondo
T Tsuji
Correspondence to:
Dr Shozo Kusachi, The First
Department of Internal
Medicine, Okayama
University Medical School,
2-5-1, Shikata-cho,
Okayama 700 Japan; email:
zqbkytmn@oka.urban.or jp
Accepted for publication
15 May 1997


plasty. There were seven men and six women, aged 42 to 75 years, mean 63 (SD 11) years. Reperfusion without flow delay was successfully established in all 13 patients. Consequently, this study did not include patients without reperfusion. Patients with associated diabetes mellitus, depressed renal function, liver disease, or malignant disorders were excluded from the study.

The lesion was located at segment 6 according to the American Heart Association classification $^{12}$ in six patients, at segment 7 in six, and at segment 2 in one. Patients in whom the responsible lesion was located in the left circumflex coronary artery were excluded from the study because left ventricular indices were evaluated on left ventriculograms obtained in the right anterior oblique view.

The interval from onset to admission ranged from 0.5 to 12 hours (mean 4.7 hours). Electrocardiographic or enzymatic evidence of reocclusion ${ }^{1314}$ was not observed in any of the patients. The patency of the infarct related artery was confirmed by follow up coronary angiography performed four weeks after the infarct.

Acute myocardial infarction was diagnosed on the basis of typical chest pain, ST segment elevation of more than $0.1 \mathrm{mV}$ in more than two leads in 12-lead electrocardiography, and a rise of both creatine kinase $(\mathrm{CK})$ and its isoenzyme $\mathrm{MB}$ to more than twofold the upper limit of the normal range. Emergency coronary angiography was performed, and reperfusion treatment with coronary angioplasty was attempted. None of the patients had cardiogenic shock that disturbed the liver circulation and caused liver damage.

\section{SERUM MMP1 AND TIMP-1}

Blood samples were drawn immediately after admission and on days $2,3,4,5,7,14$, and 28. Serum MMP-1 and TIMP-1 concentrations were measured by enzyme immunoassay. ${ }^{15} \mathrm{~A}$ one step sandwich enzyme immunoassay kit (Fuji Chemical Industries, Takaoka, Japan) for human MMP-1 using monoclonal antibodies against the MMP-1 purified from human skin fibroblasts was used to assay for MMP-1, as reported. ${ }^{15} 16$ The antibody used does not react with other collagenases. This assay system detects proMMP-1 and active MMP-1 almost equally. When reactivity with proMMP-1 was postulated as $100 \%$, relative immunoreactivities of this assay system with MMP-1 and TIMP-1 complex and with MMP-1 and TIMP-2 complex were $48 \%$ and $3 \%$, respectively. ${ }^{15} \alpha_{2}$ Macroglobulin does not interfere with this assay system. ${ }^{15}$ The detection limit of this MMP-1 assay system is $1.0 \mathrm{ng} / \mathrm{ml}$, and linearity is determined from 1 to $64 \mathrm{ng} / \mathrm{ml}$. The intraassay and interassay coefficients of variation were $2 \cdot 0-4 \cdot 3 \%$ and $<5 \%$, respectively.

Serum TIMP-1 concentration was also measured by a one step sandwich enzyme immunoassay kit (Fuji Chemical Industries, Takaoka, Japan) using a monoclonal antibody purified from bovine dental pulp TIMP which cross reacts with human TIMP-1. ${ }^{16}$ The immunoassay system for TIMP-1 reacts almost equally with free TIMP-1 and with TIMP-1 complexed with MMP-1, -2, -3, and $-9 .{ }^{16}$ The detection limit of this TIMP-1 assay system is $1.2 \mathrm{ng} / \mathrm{ml}$, and linearity is determined from 51 to $2000 \mathrm{ng} / \mathrm{ml}$. The intra-assay and interassay coefficients of variation were $1 \cdot 9-4 \cdot 5 \%$ and $2 \cdot 8-4 \cdot 3 \%$, respectively. The control range for MMP-1 and TIMP-1 was obtained from 18 age and gender matched healthy volunteers aged 62 (SD 7) years (nine men and nine women). The ranges within $1 \mathrm{SD}$ of the mean of the controls for MMP-1 and TIMP-1 and the means (SD) were $3 \cdot 2-$ $34.5 \mathrm{ng} / \mathrm{ml}(13.1 \quad(9.3) \mathrm{ng} / \mathrm{ml})$ and 109 $177 \mathrm{ng} / \mathrm{ml}(139(20) \mathrm{ng} / \mathrm{ml})$, respectively.

\section{LEFT VENTRICULOGRAPHY}

Left ventriculography was performed approximately four weeks after the onset of acute myocardial infarction. The left ventriculogram was analysed using a digitiser and a computer (Sony Graphtec Digitiser KD4030B, Tokyo, Japan). The end diastolic frame was determined as the frame nearest the peak of the $R$ wave, using an electrocardiogram recorded simultaneously on cine film. The frame with the smallest ventricular volume was taken to show the end systolic volume, and ventricular volume was calculated by a modification of Dodge's formula. ${ }^{18}$ Further, regional ventricular function was determined by centreline method. ${ }^{19}$ The regional wall motion of the infarct area was also scored visually follows: 4 =dyskinesis; $3=$ akinesis; $2=$ severe hypokinesis; $1=$ hypokinesis; $0=$ almost unaltered or mildly reduced wall motion.

CREATINE KINASE RELEASE

Blood samples for CK assay were obtained immediately upon admission and every four hours thereafter for 48 hours, and then were collected once every day. CK activities were measured by the modified Rosalski method. ${ }^{20}$ Total CK release was calculated according to a modification of a method reported by Norris et $a l^{21}$ and Shell et al. ${ }^{22}$ The duration from the onset to peak CK time was also determined. ${ }^{23}$

\section{STATISTICAL ANALYSIS}

We employed analysis of variance (ANOVA) to assess time dependent alterations in serum MMP-1 and TIMP-1 concentrations. Pearson's correlation analysis was used to examine the relations between MMP-1/ TIMP-1 and left ventricular volume indices, and Spearman's correlation analysis to determine the relation between MMP-1/TIMP-1 and the wall motion score of the infarct region. A P value of $<0.05$ was considered statistically significant. Values are given as mean (SD).

\section{Results}

MMP-1

Time course

Figure 1 shows the time dependent alteration of the serum MMP-1 concentration after acute myocardial infarction in the 13 patients examined. In five of them, MMP-1 was not 


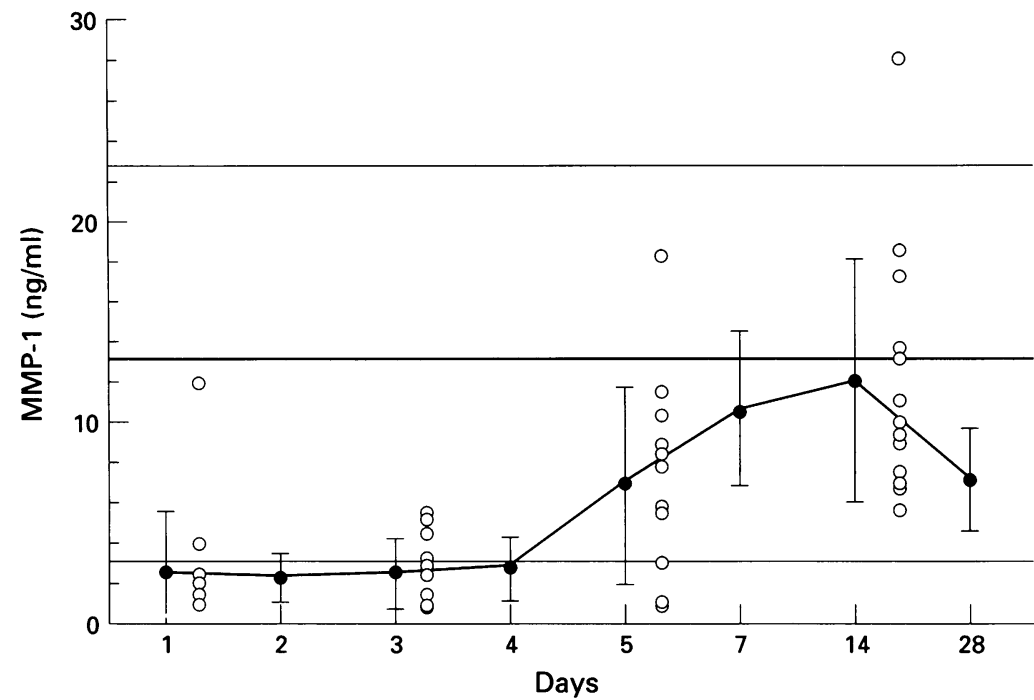

Figure 1 Sequential changes in serum MMP-1 concentrations in patients with acute myocardial infarction. Upper, middle, and lower lines indicate the concentrations at $1 S D$ above the mean control value, the mean control value, and 1 SD below the mean control value, respectively. Each bar indicates $1 S D$.

detectable on the admission day, that is, it was less than $1 \mathrm{ng} / \mathrm{ml}$ as measured by the present assay method. For further statistical analysis, undetectable concentrations of MMP-1 were specified as $1 \mathrm{ng} / \mathrm{ml}$. The duration from the onset of acute myocardial infarction to blood sampling was not correlated with the serum MMP-1 concentrations on the admission day. The average serum MMP-1 values measured at each time from the admission day to day 4 were more than $1 \mathrm{SD}$ below the mean control value. MMP-1 began to increase at day 5 and reached its maximum concentration at around day 14. It then decreased and returned to the middle control range at day 28 . ANOvA showed that this change was significant $(P<0 \cdot 01)$.

\section{Relations to left ventricular indices}

Serum MMP-1 on day 5, when it began to increase into the normal range, was negatively correlated with the left ventricular end systolic volume index and positively correlated with the left ventricular ejection fraction (fig 2). The magnitude of the rise in MMP-1 on day 5 with respect to the admission value was also inversely correlated with the left ventricular end systolic volume index $(r=-0.56, \mathrm{P}<$ $0.05)$ and positively correlated with the left ventricular ejection fraction $(r=0.59, \mathrm{P}<$ $0 \cdot 05)$. No significant relation between serum MMP-1 values and left ventricular end diastolic volume index was obtained on any day. Neither the values on the averaged peak day (day 14) nor those on the individual peak days were correlated with any of the indices.

\section{Relation to regional wall motion}

The percent area of less than $-2 \mathrm{SD} /$ chord in 13 patients ranged from $0 \%$ to $48 \%$ $(22 \cdot 51(8 \cdot 3) \%)$. The serum MMP-1 concentration on day 5 was correlated with the percentage area less than $-2 \mathrm{SD} /$ chord (fig 2). The magnitude of change in the serum values on day 5 compared to those on admission tended to be related to the area $(r=0.53$,
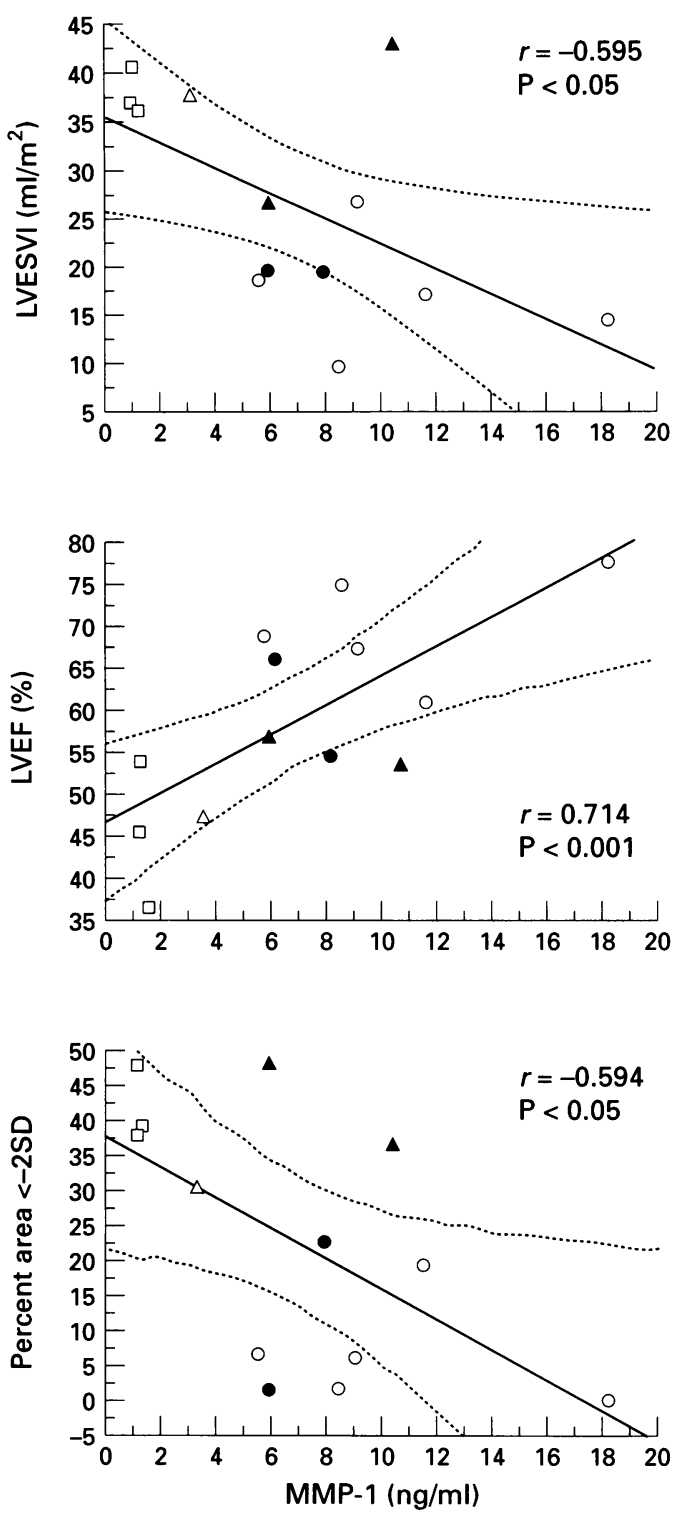

Figure 2 Relations of serum MMP-1 concentrations to left ventricular indices obtained four weeks after the onset of acute myocardial infarction. Relation of serum MMP-1 concentrations on day 5 to: (upper panel) left ventricular end systolic volume indices; (middle panel) left ventricular ejection fraction; (lower panel) percentage area less than -2 SD/chord. LVESVI, ventricular end systolic volume index; LVEF, left ventricular ejection fraction. Empty squares, filled triangles, empty triangles, filled circles, and empty circles indicate wall motion scores of $4,3,2,1$, and 0 , respectively. The lines are the regression line bounded by the $95 \%$ confidence intervals.

$0 \cdot 10>P>0 \cdot 05)$. Similarly, the serum concentrations on day 5 and the magnitude of serum concentration changes on day 5 compared to those on admission were both correlated with wall motion score $(r=-0.68, \mathrm{P}<0.05$ and $r$ $=-0.73, \mathrm{P}<0.01$, respectively).

\section{Relation to CK release}

Serum MMP-1 concentrations on day 5 and the magnitude of change of the serum concentrations on day 5 compared to the values on admission were not significantly correlated with $\mathrm{CK}$ release or time to CKmax, though the values on day 5 tended to be related to the integral $\mathrm{CK}$ release $(r=-0.55,0.10>\mathrm{P}>$ $0 \cdot 05)$. 


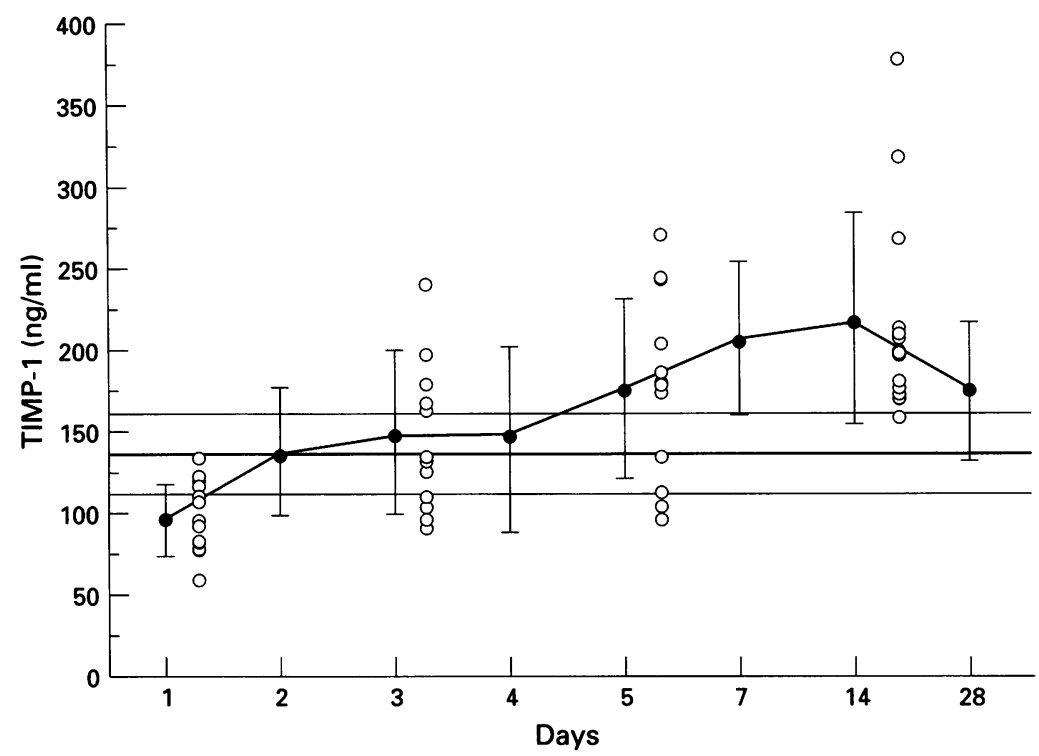

Figure 3 Sequential changes in serum TIMP-1 concentrations in patients with acute myocardial infarction. Upper, middle, and lower lines indicate the concentrations at $1 S D$ above the mean control value, the mean control value, and 1 SD below the mean control value, respectively. Each bar indicates $1 S D$.
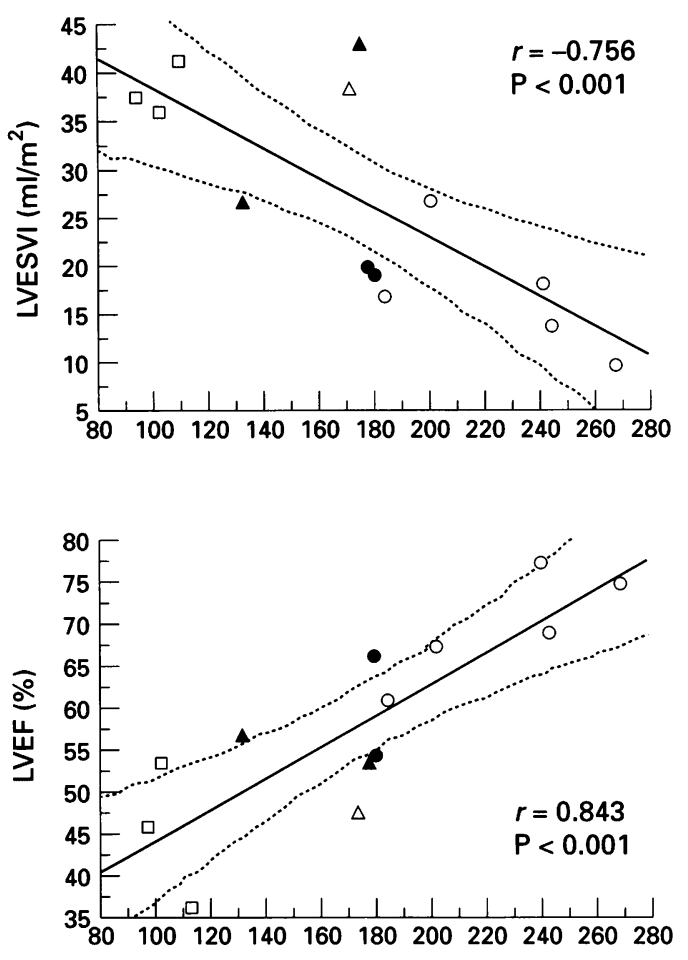

TIMP-1

Time course

The sequential changes in TIMP-1 after acute myocardial infarction in the 13 patients are shown in fig 3 . The time from onset of acute myocardial infarction to blood sampling was not correlated with serum TIMP-1 on admission. As with MMP-1, mean serum TIMP-1 at admission was more than 1 SD below the mean control value. It then increased and reached a maximum at around day 14 , subsequently decreasing to within the normal range for controls. ANOVA again showed that this change was significant $(P<0 \cdot 01)$.

\section{Relations to left ventricular indices}

As with MMP-1, serum TIMP-1 values on day 5 and day 7 were negatively correlated with left ventricular end systolic volume index $(r=-0.76, \quad \mathrm{P}<0.01$, and $r=-0.58, \quad \mathrm{P}<$ $0 \cdot 05$, respectively), and positively correlated with the left ventricular ejection fraction $(r=$ $0.84, \quad \mathrm{P}<0.01$, and $r=0.79, \quad \mathrm{P}<0.05$, respectively) (fig 4 ). The magnitude of the rise in serum TIMP-1 on day 5 and day 7 was negatively correlated with the left ventricular end systolic volume index $(r=-0.78, \mathrm{P}<0.01$, and $r=-0.62, \mathrm{P}<0.05$, respectively) and positively correlated with the left ventricular ejection fraction $(r=0.79, \mathrm{P}<0.01$, and $r=$ $0.63, P<0.05$, respectively). Neither the values on the averaged peak day (day 14) nor those on the individual peak days were correlated with any of the indices.

\section{Relation to regional wall motion}

Serum TIMP-1 values on day 5 and day 7 were correlated with percentage area less than $-2 \mathrm{SD} /$ chord $(r=-0.84, \mathrm{P}<0.01$, and $r=$ $-0.65, P<0.05$, respectively) (fig 4 ). The magnitude of the change of the serum concentrations on the respective days compared to those on admission were also correlated with

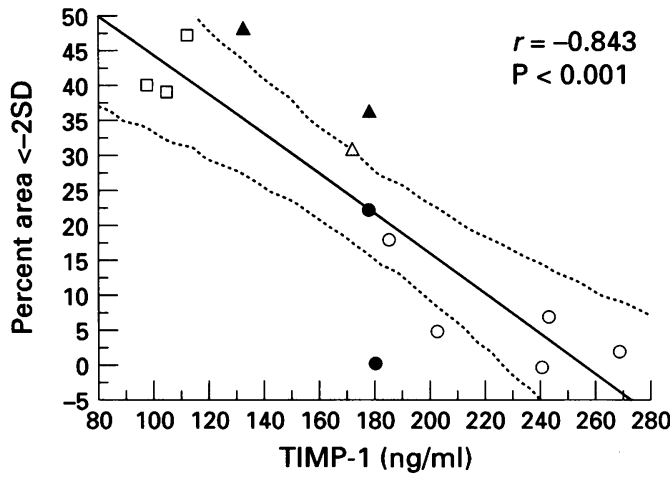

Figure 4 Relations of serum $M M P-1$ concentrations to left ventricular indices obtained four weeks after the onset of acute myocardial infarction. Relation of serum TIMP-1 concentrations on day 5 to: (upper panel) left ventricular end systolic volume indices; (middle panel) left ventricular ejection fraction; and (lower panel) the percentage area less than -2 SD/chord. LVESVI, ventricular end systolic volume index; LVEF, left ventricular ejection fraction. Empty squares, filled triangles, empty triangles, filled circles, and empty circles indicate wall motion scores of 4, $3,2,1$, and 0 , respectively. The lines are the regression line bounded by the $95 \%$ confidence intervals.

the area $(r=-0.83, \mathrm{P}<0.01$, and $r=-0.66$, $P<0.05$, respectively). Similarly, the serum lated with wall motion score $(r=-0.92, \mathrm{P}<$ 0.01 , and $r=-0.66, \mathrm{P}<0.05$, respectively). The magnitude of the serum concentration changes on day 5 and day 7 with respect to the admission values was correlated with the wall motion score $(r=-0.91, \mathrm{P}<0.01$, and $r=$ $-0.68, P<0.05$, respectively).

\section{Relation to CK release}

Neither the serum TIMP-1 on day 5 nor the magnitude of serum concentration changes on day 5 compared to the admission values was significantly correlated with the CK release or with the duration from onset to CKmax. concentrations on day 5 and day 7 were corre- 


\section{Discussion}

This study showed that the serum concentrations of both MMP-1 and TIMP-1 changed significantly and time dependently from low concentrations, below the control range, to above the control range after acute myocardial infarction. At the time when serum MMP-1 began to rise from its initially low value, serum concentrations of both MMP-1 and TIMP-1 were negatively correlated with the left ventricular end systolic volume index and positively correlated with the left ventricular ejection fraction. There were similar relations between the rise in MMP-1 and TIMP-1 concentrations from their admission values and the left ventricular end systolic volume index and ejection fraction.

The methods we used for determining serum MMP-1 and TIMP-1 are well established, ${ }^{15-17}$ and the intra-assay and interassay coefficients of variation are sufficiently small. Left ventriculography was performed in a single projection (the right anterior oblique view). Greene et $a l^{18}$ reported a good correlation between the left ventricular volumes measured using single plane and biplane methods. Moreover, we carefully selected only patients with lesions located in the left anterior descending coronary artery or the right coronary artery territory. These considerations suggest that the methods we used are valid.

The concentrations of MMP-1 on days 1 to 4 and of TIMP-1 on the admission day were more than $1 \mathrm{SD}$ below the mean for the control value. Both MMP-1 and TIMP-1 are tightly controlled by a variety of mechanisms and play important roles in extracellular matrix degradation and remodelling. Although our study did not provide any evidence relating to the mechanism by which the serum concentrations are affected in acute myocardial infarction, the low values might be explained by one or more of three mechanisms: (1) reduced synthesis, (2) increased turnover of serum MMP-1 and TIMP-1, and (3) changes in equilibrium between serum and tissue concentrations, that is, reduced release from tissue or mobilisation from serum to tissue.

\section{REDUCED SYNTHESIS}

Regarding synthesis of MMP-1, Cleutjens et $a l^{24}$ showed increased MMP-1 activity in infarct tissue by zymography, followed by increments of MMP-1 mRNA, in experimental infarction in rats. Tumour necrosis factor $\alpha$ $(\mathrm{TNF} \alpha)$ and interleukin-1 (IL-1) are known to be potent stimulators of MMP-1 at transcriptional level. ${ }^{25}$ It was also suggested that an increase in circulating cytokines contributes to raised MMP-3 concentrations in patients with rheumatoid arthritis. ${ }^{26}$ Herskowitz et al ${ }^{27}$ examined proinflammatory cytokines in the infarct by northern blotting after reperfusion following acute myocardial infarction in rats, and showed that TNF $\alpha$ mRNA and IL- $1 \beta$ mRNA in the infarct tissue both increased, with two peaks-1 to 2 hours after reperfusion and on day 7. Increased serum TNF $\alpha$ concentrations, measured by enzyme linked immunoabsorbent assay, have also been found in the early phase of human acute myocardial infarction. ${ }^{28}$ This reported evidence about the influence of cytokines on MMP suggests that the synthesis of MMP is enhanced rather than depressed. Further, increased concentrations of tissue plasminogen activator, which converts plasminogen to plasmin, have been found in the acute phase by the double antibody sandwich method, ${ }^{29}$ and plasmin is also known to activate MMP. ${ }^{7}$ Coexpression of MMP and TIMP has been shown in the myocardium $^{30}$ and human burn wounds, ${ }^{31}$ indicating that extracellular matrix degradation and reformation are regulated through the balance of concomitant expression of MMP and TIMP. These lines of evidence indicate that synthesis or activation of MMP-1 and TIMP-1 is more likely to be enhanced than reduced in the early phase of acute myocardial infarction.

\section{TURNOVER}

With respect to serum turnover of MMP-1 and TIMP-1, activated collagenase can be disrupted by $\alpha_{2}$ macroglobulin ${ }^{3233}$ or acute inflammatory reactant, and it is possible that these substances reduced the serum concentrations of MMP-1 and/or TIMP-1. However, in this study no significant correlation was obtained between either serum $C$ reactive protein or neutrophil counts and the serum concentrations of MMP-1 and TIMP-1 on the day of admission or day 5. $\alpha_{2}$ Macroglobulin has been shown not to interfere with the measurements of MMP-1 in the present assay system. ${ }^{15}$ Furthermore, the serum $\alpha_{2}$ macroglobulin concentrations do not differ in patients with acute myocardial infarction and controls. ${ }^{29}$ Although we found no reported data on the serum half life of MMP-1 and TIMP-1 in acute myocardial infarction and were unable to provide data on this from our study, we do not believe that acute inflammatory reactants and $\alpha_{2}$ macroglobulin could account for the low initial serum concentrations of MMP-1 and TIMP-1.

\section{CHANGES IN EQUILIBRIUM BETWEEN SERUM} AND TISSUE

Mobilisation of MMP-1 and TIMP-1 from the blood stream to the infarct tissue or their decreased release into to the blood stream from the tissues might explain the initial low levels, though this explanation is entirely speculative. Tyagi et $a l^{30}$ showed that MMP are present in the endothelium and subendothelial space of the endocardium and throughout the interstitial spaces of rat hearts. Cleutjens et al ${ }^{24}$ examined MMP-1 and TIMP-1 by zymography, northern blotting, and in situ hybridisation in experimental myocardial infarction in rats and postulated activation of latent MMP-1 pooled in the interstitial spaces as the initial process, and synthesis of collagenase mRNA when pooled MMP is reduced. These findings suggest that the release of MMP into serum would be reduced. They also showed that TIMP mRNA increased six hours after coronary ligation and reached a maximum level on day 2 , remaining high by day 7 . These experi- 
mental results and our observation of initially low serum concentrations of both MMP-1 and TIMP-1 lead us to speculate that activation of pooled latent MMP-1 is the initial process, but that the production of MMP-1 and TIMP-1 does not exceed their local consumption. Mobilisation from the blood stream to the interstitial spaces or reduction in release from myocardial tissue to the serum seem to be the most likely explanations for their low initial serum concentrations.

The concentrations of both MMP-1 and TIMP-1 at the time when MMP-1 began to increase into the control range were correlated with the left ventricular end systolic volume index and ejection fraction, and with the regional wall motion of the infarct, but the average peak day (day 14) concentrations or the individual peak concentrations were not correlated with any of the left ventricular indices. This suggests that the serum values of both MMP-1 and TIMP-1 reflect the healing stages of the infarct rather than the precise activity of infarct fibrogenesis. Thus, prolonged healing of the infarct might be reflected in delayed return of these serum values, resulting in low values at the time when the MMP-1 was beginning to return to the control range, whereas faster healing might be reflected in a faster return, resulting in relatively high normal range values on that day. This could explain the relation of their sequential changes to left ventricular indices, although we emphasise that this is entirely speculative.

It is well known that healing speed is correlated with infarct size. Although we found no significant correlation of serum concentrations of MMP-1 or TIMP-1 on day 5 with integral CK release, and the serum MMP-1 concentrations on day 5 showed a weak non-significant relation to the integral $\mathrm{CK}$ release, the values were correlated with percentage area less than $-2 \mathrm{SD} /$ chord, which indicates infarct area. ${ }^{19}$ Integral CK release indicates loss of myocytes, whereas it is theoretically reasonable to suppose that MMP-1 and TIMP-1 act in response to extracellular matrix damage caused by the infarct. It can also be surmised that the extracellular matrix structure differs from patient to patient with respect to the number of myocytes. This would at least partly account for the lack of a direct correlation between the integral $\mathrm{CK}$ release and sequential changes of MMP-1 and TIMP-1.

Extracellular matrix degradation and reformation is regulated through the balance between MMP and TIMP. We cannot comment on this in detail because the immunoassay we used detects not only proMMP-1 and active MMP-1 but also MMP- 1 complexed to TIMP -1 , and conversely the TIMP -1 assay system detects TIMP-1 together with TIMP-1 complexed with MMPs.

\section{LIMITATIONS OF THE STUDY}

This study has several apparent limitations. First, because of careful selection, a relatively small number of patients was included. Second, the assay system used in this study for MMP-1 could not distinguish active MMP-1 from proMMP-1 or from MMP-1 complexed with TIMPs. Similarly, the assay system for TIMP-1 could not distinguish free TIMP-1 from TIMP-1 conjugated with MMPs. The present assay method detected almost all MMP-1 and TIMP-1. Thus this study could not provide further information on various forms of MMP-1 and TIMP-1.

\section{CONCLUSION}

Our study demonstrated sequential changes in the serum MMP-1 and TIMP-1 concentrations after acute myocardial infarction, and indicated that the measurement of these enzymes may provide useful information on left ventricular remodelling.

1 Kostuk WJ, Kazamias TM, Gander MP, Simon AL, Ross $\mathrm{J}$. Left ventricular size after acute myocardial infarction:
serial changes and their prognostic significance. Serial changes and their

2 White HD, Norris RM, Brown MA, Brandt PWT, Whitelock RML, Wild CJ, et al. Left ventricular end-systolic volume as the major determinant of survival after recovery from myocardial infarction. Circulation 1987;76:44-51.

3 Weisman HF, Healy B. Myocardial infarct expansion, infarct extension, and reinfarction: pathophysiologic concepts. Prog Cardiovasc Dis 1987;30:73-110.

4 Pfeffer MA, Braunwald E. Ventricular remodeling after myocardial infarction. Experimental observations and clinical implications. Circulation 1990;81:1161-72.

5 Matrisian LM. Metalloproteinases and their inhibitors in matrix remodeling. Trends Genet 1990;6:121-5.

6 Werb Z. The biologic role of metalloproteinases and their inhibitors. In: Kuettner K, Schleyerbach R, Peyron JG, Hascall VC, eds. Articular cartilage and osteoarthritis. New York: Raven Press, 1992:295-305.

7 Dollery CM, McEwan JR, Henney AM. Matrix metalloDollery CM, McEwan JR, Henney AM. Matrix metallo-
proteinases and cardiovascular disease. Circ Res 1995;77: protein 8 .

8 Cawston TE, Galloway WA, Mercer E, Murphy G Reynolds JJ. Purification of rabbit bone inhibitor of collagenase. Biochem f 1981;195:159-65.

9 Murphy G, Cawston TE, Reynolds JJ. An inhibitor of collagenase from human amniotic fluid. Purification, characterization and action on metalloproteinases. Biochem $f$ 1981;195:167-70.

10 Murawaki Y, Kawasaki H, Burkhardt H. Serum collagenase activity in chronic liver diseases. Path Res Pract 1994;190:929-33.

11 Yoshihara Y, Obata K, Fujimoto N, Yamashita K, Hayakawa $T$, Shimmei $M$. Increased levels of stromelysin-1 and tissue inhibitor of metalloproteinases- 1 in sera from patients with rheumatoid arthritis. Arthritis Rheum 1995;38:969-75.

12 Austen WG, Edwards JE, Frye RL, Gensini GG, Gott VL, Griffith LSC, et al. A reporting system on patients evaluated for coronary artery disease. Report of the ad hoc committee for grading of coronary artery disease, Council on Cardiovascular Surgery, American Heart Council on Cardiovascular Surgery, Americar
Association. Circulation 1975;51(suppl):5-40.

13 Klootwijk P, Cobbaert C, Fioretti P, Kint PP, Simoons ML. Noninvasive assessment of reperfusion and reoccluML. Noninvasive assessment of reperfusion and reocclusion after thrombolysis in acut

14 Arnold AZ, Topol EJ. Assessment of reperfusion after thrombolytic therapy for myocardial infarction. Am Hear f 1992;124:441-7.

15 Zhang J, Fujimoto N, Iwata K, Iwata H, Sakai T, Okada Y, et al. A one-step sandwich enzyme immunoassay for human matrix metalloproteinase-1 (interstitial collagenase) using monoclonal antibodies. Clin Chim Acta 1993;219:1-14.

16 Fujimoto N, Iwata K. Enzyme immunoassay for matrix metalloproteinases and their inhibitors. Connective Tissue 1994;26:237-44 (Japanese with English abstract and tables).

17 Kodama S, Iwata K, Iwata H, Yamashita K, Hayakawa T. Rapid one-step sandwich enzyme immunoassay for tissue
inhibitor of metalloproteinases: an application for inhibitor of metalloproteinases: an application for Methods 1990;127:103-8.

18 Greene DG, Carlisle R, Grant C, Bunnell IL. Estimation of left ventricular volume by one-plane cineangiography. Circulation 1967;35:61-9.

19 Sheehan FH, Bolson EL, Dodge HT, Mathey DG, Schofer J, Woo HW. Advantages and applications of the centerline method for characterizing regional ventricular funcline method for characterizing reg
tion. Circulation 1986;74:293-305.

20 Rosalki SB. An improved procedure for serum creatine phosphokinase determination. $\mathcal{F}$ Lab Clin Med 1967;69: phosphokina

21 Norris RM, Whitlock RM, Barratt-Boyes C, Small CW. Clinical measurement of myocardial infarct size. Modification of a method for the estimation of total crea- 
tine phosphokinase release after myocardial infarction. Circulation 1975;51:614-20.

22 Shell WE, Kjekshus JK, Sobel BE. Quatitative assessment of the extent of myocardial infarction in the conscious dog by means of analysis of serial changes in serum creatine phosphokinase activity. If Clin Invest 1971;50: tine phosph

23 Horie $M$, Yasue $H$, Omote S, Takizawa A, Nagao M, Nishida $S$, et al. A new approach for the enzymatic estimation of infarct size: serum peak creatine kinase and time to peak creatine kinase activity. Am $\mathcal{f}$ Cardiol 1986; 57:76-81.

24 Cleutjens JP, Kandala JC, Guarda E, Guntaka RV, Weber $\mathrm{KT}$. Regulation of collagen degradation in the rat myocardium after infarction. $\mathcal{F} \mathrm{Mol}$ Cell Cardiol 1995;27: 1281-92.

25 Lefebvre V, Peeters-Joris C, Vaes G. Modulation by interleukin-1 and tumor necrosis factor of production of collagenase, tissue inhibitor of metalloproteinases and collagen types in differentiated and dedifferentiated articular chondrocytes. Biochim Biophys Acta 1990;1052: 366-78.

26 Manicourt D-H, Fujimoto N, Obata K, Thonar EJ. Levels of circulating collagenase, stromelysin-1 and tissue inhibitor of matrix metalloproteinases 1 in patients with rheumatoid arthritis. Relationship to serum levels of antigenic keratan sulfate and systemic parameters of inflammation. Arthritis Rheum 1995;38:1031-9.
27 Herskowitz A, Choi S, Ansari AA, Wesselingh S. Cytokine mRNA expression in postischemic/reperfused myocardium. Am f Pathol 1995;146:419-28.

28 Latini R, Bianchi M, Correale E, Dinarello CA, Fantuzzi $G$, Fresco $C$, et al. Cytokines in acute myocardial infarction: selective increase in circulating tumor necrosis faction: selective increase in circulating tumor necrosis factor, its soluble receptor, and interleukin-1

29 Vaziri ND, Kennedy SC, Kennedy D, Gonzales E. Coagu, Kennedy D, Gonzales $\mathrm{E}$.

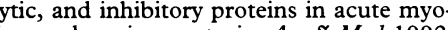
93:651-7.

30 Tyagi SC, Kumar SG, Banks J, Fortson W. Co-expression of tissue inhibitor and matrix metalloproteinase in myocardium. f Mol Cell Cardiol 1995;27:2177-89.

31 Stricklin GP, Li L, Jancic V, Wenczak BA, Nanney LB Localization of mRNAs representing collagenase and TIMP in sections of healing human burn wounds. $\mathrm{Am} \mathcal{F}$ Pathol 1993;143:1657-66.

32 Barrett AJ, Starkey PM. The interaction of $\alpha 2$-macroglobulin with proteinases. Characteristics and specificity of the reaction, and a hypothesis concerning its molecula mechanism. Biochem f 1973;113:709-24.

33 Enghild JJ, Salvesen G, Brew K, Nagase H. Interaction of human rheumatoid synovial collagenase (matrix metalloproteinase 1) and stromyelysin (matrix metalloproteinase 3) with human $\alpha 2$-macroglobulin and chicken ovostatin. $\mathcal{F}$ Biol Chem 1989;264:8779-85. 